\title{
Ulmaceae, Cannabaceae e Urticaceae das restingas do estado do Rio de Janeiro ${ }^{1}$
}

\author{
Ulmaceae, Cannabaceae and Urticaceae of restingas of the state of Rio de Janeiro
}

\author{
Leandro Cardoso Pederneiras ${ }^{2,4}$, Andrea Ferreira da Costa ${ }^{2,5}$, \\ Dorothy Sue Dunn de Araujo ${ }^{3}$ \& Jorge Pedro Pereira Carauta ${ }^{2}$
}

\begin{abstract}
Resumo
As restingas são planícies arenosas ao longo da costa litorânea que exibem uma rica e peculiar vegetação. As Ulmaceae, Cannabaceae e Urticaceae nativas do Brasil englobam plantas herbáceas a lenhosas que ocorrem preferencialmente em ambientes em regeneração. Através de pesquisa bibliográfica especializada, consultas a herbários e pesquisas de campo, objetivou-se descrever as espécies e reconhecer a distribuição, o habitat e o estado de conservação das espécies dessas famílias nas restingas fluminenses. Ulmaceae está representada por duas espécies, distribuídas em dois gêneros, Cannabaceae por quatro espécies em dois gêneros, e Urticaceae por seis espécies em quatro gêneros. Na formação de mata seca acham-se presentes oito espécies, na arbustiva fechada seis e na mata inundável uma. Dessas, sete encontram-se ameaçadas de extinção: Ampelocera glabra Kuhlm., Cecropia glaziovi Snethl, Celtis spinosa Spreng., Laportea aestuans (L.) Chew, Phyllostylon brasiliense Capan. ex Benth, Urera aurantiaca Wedd e U. nitida (Vell.) Brack.
\end{abstract}

Palavras-chave: Urticales, conservação, Mata Atlântica.

\begin{abstract}
Restingas are sandy coastal plains with a rich flora and distinct vegetation types. The native Brazilian Ulmaceae, Cannabaceae and Urticaceae include herbs, shrubs and trees from early regeneration stages. Specialized bibliography, herbarium material and field collections were used to describe the species and to determine distribution, habitat and current conservation status of species from the sandy coastal plains of Rio de Janeiro state. There are two genera and two species of Ulmaceae, two genera and four species of Cannabaceae, and four genera and six species of Urticaceae. Eight species occur in the Dry Forest Formation, six in Dense Scrub and one in Swamp Forest. Of these species, seven are threatened with extinction: Ampelocera glabra Kuhlm., Cecropia glaziovi Snethl, Celtis spinosa Spreng., Laportea aestuans (L.) Chew, Phyllostylon brasiliense Capan. ex Benth, Urera aurantiaca Wedd and U. nitida (Vell.) Brack.
\end{abstract}

Key words: Urticales, conservation, Atlantic Forest.

\section{Introdução}

Após o advento dos estudos moleculares a sistemática das famílias das Urticales (senso Cronquist 1988) sofreu algumas mudanças estruturais (Wiegrefe et al. 1998; Sytsma et al. 2002; Hadiah et al. 2008) e no Brasil ficaram evidentes principalmente na manutenção do gênero Ampelocera Klotzsch dentro de Ulmaceae e nas inclusões dos gêneros Celtis L. e Trema Lour dentro de Cannabaceae, e Cecropia Loefl. e Coussapoa Aubl. dentro de Urticaceae.
Ulmaceae, Cannabaceae, Moraceae e Urticaceae atualmente compõem o clado das Urticíneas da Ordem Rosales (APG 2009) que compreendem espécies com presença de cistólitos, flores inconspícuas, dois carpelos e ovário unilocular com um único óvulo (Judd et al. 2009). No Brasil importantes estudos demonstram suas circunscrições (Miquel 1853; Carauta 1967, 1969, 1971, 1996; Brack 1987; Romaniuc-Neto 1992; Rocha et al. 2000; Berg \& Rosselli 2005; Torres \& Luca

\footnotetext{
${ }^{1}$ Parte da dissertação de Mestrado apresentada pelo primeiro autor ao Programa de Pós-graduação em Ciências Biológicas (Botânica) do Museu Nacional/UFRJ.

${ }^{2}$ UFRJ, Museu Nacional, Depto. Botânica, Quinta da Boa Vista s.n., 20940-040, Rio de Janeiro, RJ, Brasil.

${ }^{3}$ UFRJ, CCS, Instituto de Biologia, Depto. Ecologia, Cidade Universitária, 21941-590, Rio de Janeiro, RJ, Brasil.

${ }^{4}$ Bolsista do $\mathrm{CNPq}$

${ }^{5}$ Autor para correspondência: afcosta@acd.ufrj.br
} 
2006; Romaniuc-Neto et al. 2009). A flora das restingas fluminenses não contemplou as famílias de Urticales (Segadas-Vianna et al. 1965/78), mas em listagens são reconhecidas cinco espécies (Araujo 2000).

O estado do Rio de Janeiro possui uma área de restinga de ca. $1.200 \mathrm{~km}^{2}, 2,8 \%$ da área total do estado (Araujo \& Maciel 1998), que recebe grande influência da ocupação humana e desde o século XVIII cientistas registram sua vegetação. Dentre os relatos históricos de Ulmaceae, Cannabaceae e Urticaceae nas restingas fluminenses destacam-se Celtis iguanaea (Jacq.) Sarg., Urtica dioica L., Urera mitis Miq., U. nitida (Vell.) Brack, Cecropia palmata L. em localidade desconhecida próxima ao mar no Estado do Rio de Janeiro (Vellozo 1881); Trema micrantha (L.) Blume, Laportea aestuans (L.) Chew e Boehmeria caudata Sw. em Cabo Frio (Miquel 1853) e Phyllostylon brasiliense e Cecropia sp. em Cabo Frio (Ule 1967).

Diante da diversidade de Ulmaceae, Cannabaceae e Urticaceae, pelas peculiaridades do ambiente das restingas, e ainda, pela falta de um trabalho de flora que sintetize e facilite a compreensão dessas espécies nesse bioma, esse trabalho objetivou-se descrever as espécies e reconhecer a distribuição, o habitat e o estado de conservação das espécies dessas famílias nas restingas fluminenses, dando continuidade a proposta de Segadas-Vianna et al. (1965/1978).

\section{Material e Métodos}

Foram realizadas expedições a campo entre setembro de 2007 e dezembro de 2008 . Todo o material coletado foi processado de acordo com o método usual em taxonomia (Mori et al. 1989) e depositado no herbário do Museu Nacional (R). Os herbários ALCB, CEPEC, GUA, HB, HRB, HUEFS, R, RB, RBR, SPe SPF (Thiers 2010) e UENF (Universidade Estadual Norte Fluminense), serviram de base para análise do material de Ulmaceae, Cannabaceae e Urticaceae das restingas fluminenses. Destaque-se que todos os vouchers examinados são férteis. Os caracteres morfológicos seguem as terminologias apresentadas por Vasconcelos (1969), Lawrence (1971) e Radford et al. (1974). Foi considerada apenas a variação morfológica observada nos exemplares provenientes da área de estudo. Somente as espécies nativas foram inventariadas. $\mathrm{O}$ enquadramento das famílias está de acordo com a moderna classificação (APG 2009) consolidado por diversos trabalhos (Wiegrefe et al.
1998; Sytsma et al. 2002; Hadiah et al. 2008). Para a classificação das comunidades vegetais foram usadas as definições de Araujo et al. (1998). A distribuição geográfica e o habitat foram tomados em Pederneiras (2009). A ocorrência das espécies está de acordo com a classificação de Veloso et al. (1991) e as localidades de restingas com Araujo (2000), acrescidas de Baía de Guanabara e Parati. Somente as espécies carentes de ilustração foram ilustradas.

Todas as espécies foram enquadradas como populações reprodutoras e avaliadas sob os critérios de Miller et al. (2007), onde estabelece quatro etapas (ou passos) no processo de classificação das espécies em risco de extinção regionais, sendo o passo dois, o estabelecimento da avaliação pelos critérios da Lista Vermelha da IUCN (2001), e o passo três, a aplicação dos critérios regionais da IUCN (2003). A proporção da população global presente nas restingas foi auferida calculando-se a razão do total de municípios globais sob o total de localidades de restingas fluminenses, baseado no material examinado por Pederneiras (2009). Para verificar a existência de possíveis fontes de imigração de propágulos para as restingas fluminenses, verificou-se em herbários a existência da espécie em localidades interioranas no estado do Rio de Janeiro.

\section{Resultados e Discussão Ulmaceae}

Árvores monóicas ou polígamas, inermes, sem látex. Estípulas livres, laterais, persistentes ou caducas. Folhas simples, alternas, bordo dentado a serrado, peninérveas. Inflorescências axilares, cimosas, fasciculadas, flores estaminadas na parte basal do ramo, flores funcionalmente pistiladas no ápice do ramo. Flores actinomorfas, monoclamídeas, 4-5 tépalas, geralmente unidas na base. Androceu isostêmone ou diplostêmone, estames retos no botão floral, anteras reniformes, ditecas, dorsifixas e deiscência longitudinal. Gineceu com 2 estiletes; estigma inteiro; ovário súpero, unilocular, uniovular; óvulo apical, anátropo. Fruto drupa ou sâmara.

A família Ulmaceae compreende ca. 6 gêneros e 40 espécies com ocorrência predominante na região norte temperada (Judd et al. 2009). No Brasil encontram-se 2 gêneros e 5 espécies (Souza \& Lorenzi 2005) e nas restingas fluminenses dois gêneros e duas espécies: Ampelocera glabra e Phyllostylon brasiliense. 


\section{Chave para as espécies de Ulmaceae das restingas fluminenses}

1. Lâminas foliares de bordo serrado; 5 estames; frutos alados ................... 2.1 Phyllostylon brasiliense

1. Lâminas foliares de bordo inteiro a remotamente dentado; 10 estames; frutos drupas .. 1.1 Ampelocera glabra

1. Ampelocera Klotzsch, Linnaea 20: 541. 1847.

Árvores de folhas glabras em ambas as faces, bordo inteiro a remotamente dentado. Flores com 10 estames; estiletes iguais. Fruto drupa com estames e estiletes persistentes.

Gênero exclusivamente neotropical ocorrente nas elevações médias e baixas das florestas do México a Bolívia, da costa sudeste brasileira e Antilhas. Compreende nove espécies no total, para o Brasil apenas três (Todzia 1989). Nas restingas fluminenses Ampelocera é representado por uma única espécie.

1.1 Ampelocera glabra Kuhlm., Arch. Jard. Bot. Rio de Janeiro 4: 351, pl. 28.1925.

Árvores ca. $17 \mathrm{~m}$ de alt. Estípulas 2-3 mm, glabras. Folhas com pecíolos 3-5 mm, glabros, canaliculados; lâminas elípticas, 7,5-10×3-3,7 cm, coriáceas, lustrosas, base arredondada, ápice agudo a cuspidado, bordo inteiro a inconspicuamente dentado no ápice, nervuras secundárias 7-9 pares. Inflorescências geminadas com 3 flores por cimeira, 2-3 mm; bráctea basal 3-3,5 mm, as secundárias 1$1,5 \mathrm{~mm}$, ápice agudo. Flores bissexuais, 5 tépalas; 10 estames livres; ovário súpero; estigma filamentoso no botão. Frutos ovóides, glabros, assimétricos, 13-15 mm de diâm., esverdeados.

Material examinado: RIO DE JANEIRO: Cabo Frio, Condomínio Florestinha, 6.XII.2001, G.S.Z. Rezende 69 et al. (RB).

A espécie é endêmica do Brasil, encontrada na floresta ombrófila densa e estacional semidecidual, nos estados da Bahia, Minas Gerais, Espírito Santo e Rio de Janeiro. Nas restingas fluminenses ocorre somente em uma localidade de restinga (Barra de São João), numa extensão de ocorrência ca. 0,6 km², na Formação de Mata Seca, sob continuo decréscimo de sua área de ocupação por causa de construções de residências, empreendimentos e estradas. Após algumas excursões nessa localidade, a espécie não foi reencontrada. A proporção da população global presente nas restingas é de $14 \%$. A quantidade de registros de herbários existentes das vizinhanças das restingas (Kuhlmann 1221, 6794 RB;
G.M.Nunes $80 \mathrm{RB}$ ) e a atual deterioração desses locais (p. ex. Bairro das Laranjeiras, Rio de Janeiro) indicam escassez de fontes de imigração de propágulos e, por tanto, não modifica a classificação do passo dois. Criticamente em perigo, CEB1.

2. Phyllostylon Capan. ex Benth. \& Hook.f., Gen. Pl. 3: 352. 1880.

Árvores ou arbustos. Folhas com lâminas serradas. Flores com 5 tépalas; 5 estames opostos a tépala; estiletes desiguais. Frutos sâmaras, duas asas, desiguais, a maior, membranácea, falciforme, a menor na base.

Trata-se de um gênero pequeno ocorrente na América Tropical, com apenas duas espécies, cujo hábitat preferencial constitui-se as florestas arbustivas secas (Todzia 1992). Nas restingas fluminenses Phyllostylon é representado por uma única espécie.

2.1 Phyllostylon brasiliense Capan. ex Benth. \& Hook.f., Gen. Pl. 3: 352. 1880.

Árvores ca. $3 \mathrm{~m}$. Estípulas intrapeciolares, ca. $1 \mathrm{~mm}$. Folhas com pecíolos 1-2 mm, pubescentes alvos; lâminas elíptico-ovadas, 2-3,2 ×0,6-1 cm, base obtusa, ápice agudo, bordo serrado, face adaxial com tricomas sobre as nervuras, abaxial pubérula, principalmente nas nervuras; nervuras secundárias 7-9 pares. Frutos 2,8-3,4 cm, glabros a pubérulos, verdes a avermelhados.

Material examinado: RIO DE JANEIRO: Búzios, condomínio Búzios Bauen Club, 7.XI.1985, H.C.Lima 5188 et al. (RB). Rio de Janeiro, São Cristóvão, 28.X.1890, A.Glaziou s.n. (RB 6842).

Phyllostylon brasiliense é endêmica do Brasil, encontrada na floresta ombrófila densa de Pernambuco ao Rio de Janeiro e na estacional semidecidual de Minas Gerais. Nas restingas fluminenses foi registrada em duas localidades de restinga (Cabo Frio e Baía de Guanabara), mas somente encontrada em Cabo Frio atualmente, comprimida numa área de ocupação inferior a $10 \mathrm{~km}^{2}$, provavelmente em formação de mata seca, sob contínuo decréscimo por causa de construções 
de empreendimentos hoteleiros, estradas e estacionamentos. A proporção da população global presente nas restingas é de $25 \%$. Atualmente há somente um vestígio de ocorrência em regiões vizinhas as restingas fluminenses, na Ilha da Conceição, Niterói (J.P.P.Carauta, comunicação pessoal), e que não indica uma potencial fonte de imigração de propágulos, por tanto, não modifica a classificação do passo dois. Criticamente em perigo, CEB2ab(ii,iii).

\section{Cannabaceae}

Árvores ou arbustos lenhosos, eretos ou escandentes, monóicos ou polígamos, sem látex. Estípulas interpeciolares, livres. Folhas simples, alternas, geralmente dísticas, base geralmente assimétrica, bordo dentado a serrado, nervura secundária basal alongada até o terço superior.
Inflorescência axilar, cimosa, fasciculada, flores estaminadas agrupadas, flores pistiladas frequentemente geminadas ou solitárias, no ápice do ráque. Flores actinomorfas, monoclamídeas, 4-5 tépalas, livres ou unidas na base, isostêmone, com ou sem pistilódios ou estaminódios. Androceu com estames opostos a tépala, retos no botão; anteras reniformes, ditecas, dorsifixas com deiscência longitudinal. Gineceu com 2 estiletes, terminais; ovários súperos, uniloculares, uniovulares; óvulo apical, anátropo. Frutos drupas, com estilete persistente.

A família Cannabaceae compreende ca. 11 gêneros e 180 espécies amplamente dispersas em regiões tropicais e temperadas (Judd et al. 2009). No Brasil encontram-se dois gêneros e ca. 15 espécies (Souza \& Lorenzi 2005) e nas restingas fluminenses dois gêneros e quatro espécies.

\section{Chave para as espécies de Cannabaceae das restingas fluminenses}

1. Ausência de acúleos nos ramos; bordo da lâmina foliar inteiramente serrado; flores com estigma inteiro 4.1 Trema micrantha

1'. Presença de acúleos nos ramos; bordo da lâmina foliar crenado-serrado somente na metade superior; flores com estigma bífido.

2. Lâminas foliares de face abaxial tomentoso-ferrugínea

3.1 Celtis brasiliensis

2'. Lâminas foliares de face abaxial glabra a pubérula.

3. Lâminas até 3,5 cm de compr., nervuras secundárias 3-4 pares

3.3 Celtis spinosa

3'. Lâminas acima de 3,5 cm de compr., nervuras secundárias 5-7 pares

3.2 Celtis iguanaea

3. Celtis L., Sp. Pl., 2: 1043. 1753.

Arbustos escandentes, ramos armados; acúleos glabros, retos ou curvos, solitários ou geminados. Folhas elípticas a ovadas, base simétrica a assimétrica, bordo na metade superior crenadoserrado, domácias marsupiformes, inconspícuas nas nervuras secundárias e terciárias. Flores estaminadas com pistilódio; flores pistiladas com estaminódios, estigma bífido.

Celtis distribui-se nas regiões temperadas a tropicais do mundo, com ca. 70-100 espécies (Burger 1977; Romanczuk \& Martínez 1978). Na América do Sul são estimadas de 6-30 espécies (Miquel 1853; Planchon 1873; Berg \& Dahlberg 2001) e nas restingas fluminenses ocorrem três espécies.
3.1 Celtis brasiliensis (Gardner) Planch., Ann. Sci. Nat., Bot., sér. 3, 10:310. $1848 . \quad$ Fig. 1a-b Arbustos 3-7 m de alt. Estípulas 2-3 mm, tomentoso-ferrugíneas, caducas. Folhas com pecíolos 3-9 mm, pubérulos a tomentosos; lâminas elípticas a ovadas, $3-7 \times 1,6-4,5 \mathrm{~cm}$, base arredondada ou subcordada, frequentemente assimétrica, ápice agudo, cuspidado ou mais raramente arredondado, bordo serrado na metade superior, face adaxial escabrosa, abaxial tomentosoferrugínea, nervuras secundárias 4-6 pares, nervura basal longa passando da metade da lâmina; domácias tomentoso-ferrugíneas. Flores brancas. Frutos geminados, elipsóides, glabros, 9-12×7$8 \mathrm{~mm}$; pedúnculos ca. $4-6 \mathrm{~mm}$, glabros. 


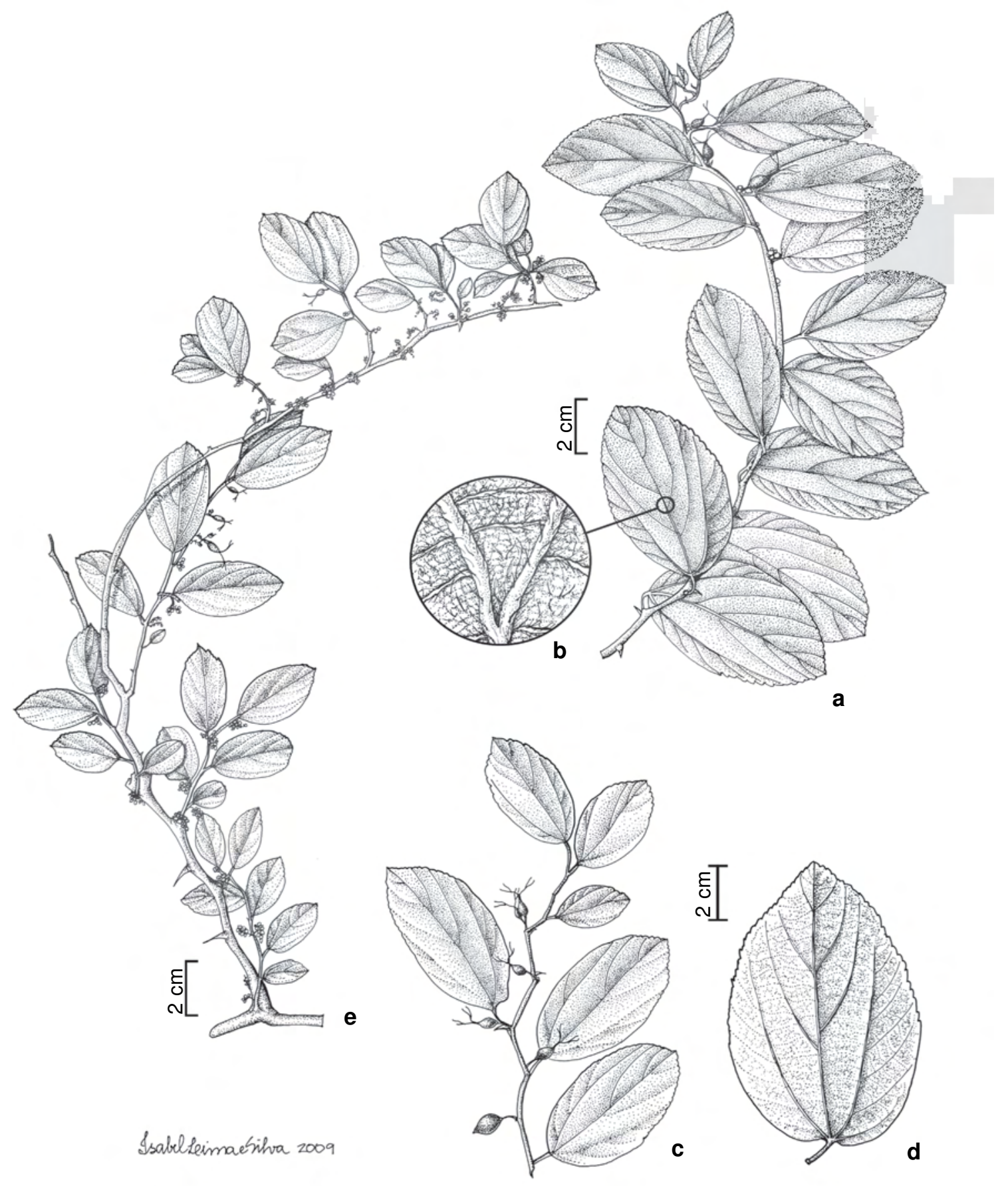

Figura 1 - a-b. Celtis brasiliensis (Gardner) Planch. - a. ramo; b. detalhe do indumento da lâmina foliar (V.S.Fonseca 20 et al.). c-d. Celtis iguanaea (Jacq.) Sarg. - c. ramo; d. folha da base do ramo (L.C.Pederneiras 475). e. Celtis spinosa Spreng - e. ramo (Araujo 9474).

Figure 1 - a-b. Celtis brasiliensis (Gardner) Planch. - a. twig; b. lamina indumentum (V.S.Fonseca 20 et al.). c-d. Celtis iguanaea (Jacq.) Sarg. - c. twig; d. leave of twig base (L.C.Pederneiras 475). e. Celtis spinosa Spreng - e. twig (Araujo 9474). 
Material examinado: RIO DE JANEIRO: Cabo Frio: Praia do Peró, Carauta 7349 et al. (R); Restinga do Peró, 17.IX.1968, D.Sucre 3675 (GUA, RB). Mangaratiba, Restinga de Marambaia, 6.V.2008, L.C.Pederneiras 428, 429 et al. (R). Niterói, Jurujuba, 14.VIII.1881, J.Saldanha 5808 (R). Rio das Ostras, Restinga da Praia Virgem, 25.IX.1999, H.N.Braga 568 (RB). Rio de Janeiro: Restinga da Barra da Tijuca, 16.V.1932, J.G.Kuhlmann s.n. (RB 55416); Restinga de Jacarepaguá, 15.X.1958, E.Pereira 4411 et al. (GUA, RB). Saquarema, R.E.E.Jacarepiá, 9.III.1993, V.S.Fonseca 20 et al. (RB).

Celtis brasiliensis cresce no Brasil, da Bahia até Santa Catarina, e nos estados interioranos do Mato Grosso, Mato Grosso do Sul, Minas Gerais, Goiás e Distrito Federal. Ocorre também no Paraguai e Bolívia. Habitam as matas secundárias da floresta ombrófila densa Atlântica, floresta estacional semidecidual e decidual, cerrado e caatinga. Nas restingas fluminenses são encontradas cinco localidades (Barra de São João, Cabo Frio, Maricá, Rio de Janeiro, Marambaia), com extensão de ocorrência de ca. $5000 \mathrm{~km}^{2}$, em matas secundárias, em clareiras ou bordas de estradas dentro da formação arbustiva fechada, em áreas de restingas perturbadas em processo de regeneração. A proporção da população global presente nas restingas é ca. $15 \%$. Cumpre com os critérios de VU B1, mas a espécie ocorre nas vizinhanças das restingas, ou seja, uma fonte de imigração de propágulos que diminui uma categoria. Próximo a ameaçado, NT.

Pode ser confundido com Celtis fluminense Carauta ou C. chichape (Wedd.) Miq., mas a primeira tem folhas maiores e mais alongadas (ca. de $8 \mathrm{~cm}$ de compr.), ápice predominantemente agudo e ramos e frutos densamente tomentosoferrugíneo, a segunda tem folhas menores (ca. 3 cm de compr.) e arredondadas.

\subsection{Celtis iguanaea (Jacq.) Sarg., Silva 7: 64. 1895.}

Fig. 1c-d

Arbustos 3-6 m de alt. Caule principal sem espinhos. Ramos escandentes, glabros ou providos de tricomas filiformes, até $1,5 \mathrm{~mm}$ de compr., relativamente grossos, esparsamente distribuídos; acúleos 0,5-3 cm. Estípulas terminais 2,5-3 mm, pubescentes, alvas, caducas. Folhas com pecíolos 3-11 mm, glabros, raramente pubérulos; lâminas ovadas ou elípticas, 3,5-6(7) ×2,2-4 cm, subcoriáceas, base arredondada, cordiforme, assimétrica, ápice agudo, bordo dentado-serrado na metade superior, face adaxial escabrosa e abaxial glabra, glabrescente ou pubérula, lisa; nervuras secundárias 5-7 pares. Flores verde-amareladas. Frutos elipsóides, glabros, geminados ou solitários, 8-12 × 6-8 mm, verdes, amarelos ou brúneos; pedúnculo $(1,5) 2-8 \mathrm{~mm}$, glabro.

Material examinado: RIO DE JANEIRO: Angra dos Reis, Praia do Sul, 11.III.1986, D.Araujo 7291 et al. (GUA). Araruama, próximo a Lagoa Pernambuca, 3.XII.2007, D.Araujo 11049 (GUA). Búzios, Estrada para Búzios, 22.I.1967, D.Sucre 1447 (RB). Cabo Frio, Condomínio Florestinha, 9.VI.2008, L.C.Pederneiras 463 et al. (R). Mangaratiba, Restinga de Marambaia, Campo de prova da Marambaia, 20.VI.2002, L.F.T.Menezes 972 (RBR). Maricá, APA de Maricá, 2.IX.2008, L.C.Pederneiras 474, 475, 481 (R). Rio das Ostras, Praia da Virgem, 8.II.2001, H.N.Braga 1799 (R). Rio de Janeiro: Pedra de Guaratiba, APA da Briza, 5.II.1998, D.Araujo 10616 (GUA); Estrada do Pontal, 23.VII.1968, D.Sucre 3307 (RB); Grumari, 15.III.1991, D.Araujo 9287 et N.C.Maciel (GUA); Leblon-Gávea, 1925, J. Kuhlmann s.n. (RB 19153); Restinga da Tijuca, 7.IV.1945, O.X.B.Machado s.n. (RB 76283). Saquarema, Ipitangas, 28.II.2008, L.C.Pederneiras 376 et al. (R).

Cestis iguanaea distribui-se do leste dos Estados Unidos, América Central, Antilhas até o sudeste da América do Sul, em florestas perenes ou decíduas, em formações úmidas ou secas, do nível do mar até 1200 m de altitude (Burger 1977). No Brasil, ocorre nas matas secundárias da floresta ombrófila densa Atlântica e Amazônica, floresta ombrófila mista, estacional semidecidual e decidual, cerrado e caatinga. Nas restingas fluminenses ocorre em oito localidades (Barra de São João, Cabo Frio, Maricá, Baía de Guanabara, Rio de Janeiro, Grumari, Marambaia e Praia do Sul), numa área de ocupação ca. $1000 \mathrm{~km}^{2}$, nas bordas de estradas dentro da formação arbustiva fechada, em áreas perturbadas, em processo de regeneração. A proporção da população global da espécie presente nas restingas não foi estimada porque não foram ainda visitados todos os herbários das regiões de sua distribuição geográfica. A espécie ocorre nas vizinhanças das restingas, sendo uma fonte de imigração de propágulos. Não ameaçada, LC.

Celtis iguanaea apresenta uma grande variação na forma e tamanho foliar, observada num mesmo indivíduo. A lâmina possui 2,5-9,2 cm, base subcordiforme ou arredondada, simétrica ou assimétrica, ápice cuspidado, agudo ou arredondado, bordo denteado-serrado da metade ou somente no terço superior. A densidade do indumento varia nos indivíduos estudados. A face abaxial da lâmina é glabra, glabrescente ou pubérula, nunca tomentosa ferrugínea de aspecto viloso como em $C$. fluminense. 
3.3 Celtis spinosa Spreng., Syst. Veg., ed. 16, 1: 931.1825.

Fig. 1e

Arbustos 2,5-5 $\mathrm{m}$ de alt., muito ramificados. Estípulas 2-3 mm, tomentosas. Folhas com pecíolos 3-5 mm, glabros a pubescentes; lâminas elípticas, raramente ovadas, $2,1-3,3 \times 1,3-1,6 \mathrm{~cm}$, base arredondada a cuneada, ápice agudo, bordo crenado-serrado no terço superior, face adaxial escabrosa, abaxial pubérula a glabra, nervuras secundárias 3-4 pares. Flores verde-amareladas. Ovário glabrescente a pubescente.

Material examinado: RIO DE JANEIRO: Saquarema: Cômoros da Lagoa Vermelha, orla, 20.X.1988, D.Araujo 8624 et J.Mauro (GUA); R.E.E.Jacarepiá, próximo a Itaúna, orla, 29.X.1991, D.Araujo 9474 et C.Farney (GUA).

Celtis spinosa cresce em floresta ombrófila densa atlântica e estacional semidecidual, do Rio de Janeiro ao leste da Argentina, e também em Cuiabá, Mato Grosso. Nas restingas fluminenses ocorre em apenas uma localidade de restinga (Cabo Frio), numa área de ocupação inferior a $5 \mathrm{~km}^{2}$, em formação arbustiva fechada. A proporção da população global da espécie presente nas restingas não foi estimada porque não foram visitados todos os herbários das regiões de sua distribuição geográfica. A espécie ocorre no Parque Estadual da Serra da Tiririca, Niterói, sendo uma fonte de imigração de propágulos e, por isso, diminui-se uma categoria do passo dois. Em perigo, EN B2a,b(ii,iii).

Celtis spinosa assemelha-se a $C$. chichape, mas aquela tem folhas de ápice agudo (vs. ápice arredondado). Berg \& Dahlberg (2001) sinonimizam C. spinosa com C. iguanaea, mas ao analisar a obra princeps e a fotografia do tipo (B-100247968) notamse diferenças na forma da folha. C. spinosa possue folhas pequenas, até $3,3 \mathrm{~cm}$ de compr. e nervuras secundárias 3-4 pares (vs. folhas acima de 3,5 cm e nervuras secundárias de 5-7 pares).

4.Trema Lour., Fl. Cochinch. 2: 539, 562-563. 1790.

Árvores ou arbustos, inermes. Folhas ovadolanceoladas, base marcadamente assimétrica, bordo inteiramente serrado. Flores estaminadas com pistilódio; flores pistiladas sem estaminódios, estigma inteiro.

Trema distribui-se nos trópicos e subtrópicos do mundo. As espécies são frequentemente de morfologia variável e de difícil taxonomia. O número total de espécies é incerto, estima-se ca. 30-55 espécies (Burguer 1977). Nas Américas ocorrem de 4 a 5 espécies e no Brasil provavelmente uma (Torres \& Luca 2006).
4.1 Trema micrantha (L.) Blume, Mus. Bot. 2:58. 1856. Árvores a arbustos, 2-7 m de alt. Estípulas 1-3 mm, persistentes a caducas. Folhas com pecíolos 6-10 mm, pubescentes, canaliculados; lâminas 6-9(10,5) ×2,3-3,4 cm, base assimétrica, arredondada, ápice acuminado, cuspidado, bordo serrado desde a base, face adaxial escabrosas, ocasionalmente lustrosa, e abaxial tomentosas a escabrosas; nervuras secundárias 3-5 pares. Inflorescências com raque verde, pubescente, alva; brácteas persistentes no ramo, ca. $1 \mathrm{~mm}$, vináceas a bruneas. Flores com tépalas verdes, pubescentes; estames e anteras alvos, estígmas 2. Frutos 23,5 mm de diâm., glabros, alaranjados, perigônio e estilete persistentes.

Material examinado: RIO DE JANEIRO: Angra dos Reis, Praia do Sul, 13.VI.1984, D.S.Pedrosa 1111 et H.Q.Boudet (GUA). Arraial do Cabo, Restinga de Massambaba, 4.III.2008, L.C.Pederneiras 380 et al. (R). Búzios, Restinga entre a praia de Manguinhos e Rasa, 11.I.1979, G.Martinelli 5620 (RB). Cabo Frio, Condomínio Florestinha, 2.IV.2008, L.C.Pederneiras 400 et M.S.Faria (R). Carapebus, PNRJ, Mata do Córrego Fundo, 19.X.1995, M.G.Santos 591 et al. (RB). Mangaratiba, Restinga de Marambaia, em frente ao hotel, 5.V.2008, L.C.Pederneiras 422 et al. (R). Maricá, APA de Maricá, 2.IX.2008, L.C.Pederneiras 476, 477 (R). Niterói, Jurujuba, 8.X.1875, (R 39098). Rio das Ostras, ARIE Itapebuçus, VII.2004, A.Oliveira 888 et D. Oliveira (RB). Rio de Janeiro: Restinga de Grumari, 24.II.1972, J.A.Jesus 1314 (RB); Restinga de Jacarepaguá, 31.X.1969, D. Sucre 6152 et Graziela (GUA); Recreio dos Bandeirantes, 25.XI.1969, Segadas-Vianna 4683 (R); Restinga da Tijuca, 5.V.1945, O.X.B..Machado 1485 (RB); Guaratiba, Praia de Guaratiba, 5.I.1934, Sampaio et al. (R 39093). Saquarema, R.E.E.Jacarepiá, 21.V.1996, A.Q.Lobão 105 et al. (RB).

Trema micrantha ocorre desde o México até o sul da América do Sul (Burger 1977). No Brasil, distrubui-se nas matas secundárias da floresta ombrófila densa Atlântica e Amazônica, floresta ombrófila aberta, estacional semidecidual e decidual, cerrado e caatinga. Nas restingas fluminenses ocorre em nove localidades (Macaé, Barra de São João, Cabo Frio, Maricá, Baía de Guanabara, Rio de Janeiro, Grumari, Marambaia e Praia do Sul), numa extensão de ocorrência ca. $6900 \mathrm{~km}^{2}$, nas bordas de estradas dentro da Formação Arbustiva Fechada, em áreas perturbadas e em processo de regeneração. A proporção da população global da espécie presente nas restingas não foi estimada porque não foram visitados todos os herbários das regiões de sua distribuição geográfica. Cumpre com os critérios de VU B1, mas 
a espécie ocorre nas vizinhanças das restingas, sendo uma fonte de imigração de propágulos. Próxima a ameaçada, NT.

\section{Urticaceae}

Ervas, arbustos ou árvores, monóicas ou dióicas, inermes ou armadas, ramos e folhas com acúleos e tricomas urticantes, laticíferos restritos a casca, látex branco ou hialino. Estípulas intrapeciolares, inteiras ou partidas no ápice, ou conadas e caducas deixando cicatriz amplexicaule. Folhas simples, alternas, inteiras ou lobadas, peninérveas ou palminérveas, bordo liso a dentado. Inflorescências axilares, em panículas, dicásios, capítulos globosos ou amentos. Flores unissexuais, monoclamídeas, actinomorfas ou zigomorfas, 2-5 tépalas livres ou concrescidas, isostêmones, com ou sem pistilódio. Androceu com filetes retos ou curvos no botão, opostos as tépalas; anteras reniformes, ditecas, dorsifixas, deiscência longitudinal. Gineceu com estilete único; estigmas filiformes ou penicilado-capitados, terminais; ovários súperos, uniloculares; óvulos basais, ortótropos. Frutos aquênios.

A família Urticaceae compreende ca. 54 gêneros e 1160 espécies amplamente dispersas em regiões tropicais e temperadas (Judd et al. 2009). No Brasil encontram-se 12 gêneros e ca. 80 espécies (Souza \& Lorenzi 2005) e nas restingas fluminenses quatro gêneros e seis espécies.

\section{Chave para as espécies de Urticaceae das restingas fluminenses}

1. Ervas ou arbustos providos de tricomas urticantes.

2. Plantas monóicas; inflorescências paniculadas; tépalas com tricomas translúcidos; acúleos ausentes 7.1 Laportea aestuans

2'. Plantas dióicas; inflorescências em dicásios; tépalas glabras; acúleos presentes.

3. Folhas ovadas, bordo regularmente dentado, ou crenado quando jovem; inflorescências em dicásios perfeitos, estaminadas terminadas em glomérulos, pistiladas uniformes; flores pistiladas com estilete reto 8.1 Urera aurantiaca

3'. Folhas elípticas, bordo ondulado-dentado; inflorescências em dicásios irregulares, estaminadas escorpióides, pistiladas congestas ao redor do caule; flores pistiladas com estilete curvo...

1'. Árvores sem tricomas urticantes.

8.2 Urera nitida

4. Ramos fistulosos; folhas palmatilobadas, palminérveas; inflorescências em amentos.

5. Estípulas terminais vináceas; amentos alaranjados ou amarelados ..... 5.1 Cecropia glaziovi

5'. Estípulas terminais alvas, verde-claras ou rosadas; amentos estaminados verde-amarelados a grisáceos 5.2 Cecropia lyratiloba

4'. Ramos medulosos; folhas inteiras, peninérvias; inflorescências capitadas ou discóide 6.1 Coussapoa microcarpa

5. Cecropia Loefl., Iter Hispan. 272. 1758.

Árvores dióicas, ramos fistulosos, sem acúleos e tricomas urticantes, látex hialino. Estípula conada e caduca deixando cicatriz amplexicaule. Folhas alternas a espiraladas, palmatilobadas, palminérveas, bordo liso, presença de triquílios na base do pecíolo (denso indumento produtor dos "Corpúsculos de Müller"). Inflorescência em espatas pareadas exibindo um conjunto de amentos ao amadurecer. Flores actinomorfas com perigônio tubuloso; estaminadas 2-lobada, 2 estames, filetes retos no botão, ausência de pistilódio; pistiladas com estigma penicilado-capitado.
Gênero neotropical com 61 espécies reconhecidas, distribuídas nas florestas úmidas e semi-úmidas como árvores pioneiras (Berg \& Rosselli 2005). Nas restingas fluminenses está representado por duas espécies.

5.1 Cecropia glaziovi Snethl., Notizbl. Bot. Gard. Berlin-Dahlem 8:358. 1923.

Árvores ca. $10 \mathrm{~m}$ de alt. Estípula terminal vermelha a vinácea, 7,5-20 $\mathrm{cm}$ de compr., pubescente ou glabra. Folha com pecíolo $19-55 \mathrm{~cm}$, pubescente, glândula basal 5-16 $\mathrm{mm}$ pubescente ferrugínea; lâmina de ápice agudo, lobo maior 25- 
$40 \mathrm{~cm}$ de compr., bordo 10-12-lobado, face adaxial glabra e abaxial pubescente; nervura primária frequentemente vermelha, nervuras secundárias 2425 pares no lobo maior. Inflorescência protegida por espata hirsuta alva a amarelo-escuro; estaminada 4-7 amentos, amarelos a alaranjados, tomentosos, pedúnculo primário $3,9-12 \mathrm{~cm}$, secundários 7-10 mm de compr.; pistilada 4-5 amentos, pedúnculo primário 6-7,5 $\mathrm{cm}$, secundário séssil.

Material selecionado: RIO DE JANEIRO: Búzios, 3.IV.2004, A.F.P.Machado 161 et al. (R). Cabo Frio, 30.X.2008, L.C.Pederneiras 516 et R.W.Lacerda (R). Rio de Janeiro, 18.XII.1979, J.C.Andrade 25 (GUA).

Cecropia glaziovi é endêmica do Brasil, encontrada na floresta ombrófila densa atlântica e estacional semidecidual, da Bahia ao Rio Grande do Sul. Nas restingas fluminenses ocorre em duas localidades (Barra de São João, Cabo Frio e Rio de Janeiro), com extensão de ocorrência ca. $3500 \mathrm{~km}^{2} \mathrm{e}$ área de ocupação ca. $10 \mathrm{~km}^{2}$, na formação de Mata Seca em processo de regeneração, próximas a encostas florestadas, como no Recreio dos Badeirantes e na Ilha de Marambaia. A proporção da população global presente nas restingas é de 7\%. A espécie ocorre nas vizinhanças das restingas, sendo uma fonte de imigração de propágulos e, por isso, diminui-se uma categoria do passo dois. Vulnerável, VU B1+2a,b (ii,iii).

5.2 Cecropia lyratiloba Miq. in Mart., Fl. bras. 4(1): 144. 1853.

Árvores 1-9,5 m alt.. Caule com lenticelas esparsas. Estípula terminal alva, verde-claro ou rosada, $8,5-12,5 \mathrm{~cm}$ de compr. Folha com pecíolo 10,5-18,5 cm, glabro, glândula basal 6-14 mm; lâmina com ápice agudo a mucronado, lobo maior $13-20 \mathrm{~cm}$ de compr., subcoriáceo, bordo 9-10-lobado, face adaxial áspero verde e abaxial pubescente, verde-claro a alva; nervuras secundárias 14-17 pares no lobo maior. Inflorescência protegida por espata verde-clara a alva quando jovem; pedúnculo primário de $3-6,2 \mathrm{~cm}$; secundário séssil, ca. $5 \mathrm{~mm}$ de compr.; $10-11$ amentos estaminados por espata, 3,2-4,6 cm, verde-amarelados a grisáceos; 4-5 amentos pistilados, 8-9,4 cm, verdeclaro. Flores estaminadas com perigônio concrescido, bipartido no ápice. Flores pistiladas envoltas de pêlos aracnóideos alvos, estilete extrorso. Fruto oblongo, 2-2,2 $\mathrm{mm}$.

Material selecionado: RIO DE JANEIRO: Angra dos Reis, Praia do Leste, 15.V.1984, D.Araujo 6274 (GUA). Arraial do Cabo, 3.III.2008, L.C.Pederneiras 377 et al. (R). Cabo Frio, 29.X.2008, L.C.Pederneiras 499 et R.W.Lacerda (R). Carapebus, Parque de Jurubatiba,
9.XI.1981, D.Araujo 4661 et al. (GUA). Macaé, 31.X.2008, L.C.Pederneiras 533 et R.W.Lacerda (R). Mangaratiba, Restinga de Marambaia, 6.V.2008, L.C.Pederneiras 439 et al. (R). Maricá, APA de Maricá, 23.X.2007, L.C.Pederneiras 326 et al. (R). Quissamã, 5.V.2005, L.C.Pederneiras 177 et al. (R). Rio das Ostras, 12.XII.2002, H.N.Braga 4250 (R). Rio de Janeiro, Restinga de Jacarepaguá, 7.V.1958, E.Pereira 3715 et al. (HB). São João da Barra, 1.XI.2008, L.C.Pederneiras 545 et R.W.Lacerda (R). Saquarema, Jacarepiá, 17.I.2008, L.C.Pederneiras 359 et A.F.P.Machado (R).

Cecropia lyratiloba é nativa do Brasil, encontrada na floresta ombrófila densa de Pernambuco ao Paraná, na estacional semidecidual e decidual, e no cerrado de Minas Gerais, Goiás e Distrito Federal. Nas restingas fluminenses ocorre em oito localidades (São João da Barra, Macaé, Barra de São João, Cabo Frio, Maricá, Rio de Janeiro, Marambaia e Praia do Sul), com extensão de ocorrência ca. $22.000 \mathrm{~km}^{2}$, em áreas degradadas da Formação de Mata Seca, Mata Inundável e Arbustiva Fechada. A proporção da população global presente nas restingas é de $22 \%$. A espécie ocorre nas vizinhanças das restingas, sendo uma fonte de imigração de propágulos. Não ameaçada, LC.

Andrade \& Carauta (1981) observaram, na restinga da Barra da Tijuca, indivíduos com porte menor (até $4 \mathrm{~m}$ ), apenas uma ramificação candelabriforme e coloração da estípula verde-clara, conferindo a esses indivíduos nova variedade (Cecropia lyratiloba var. nana Carauta \& Valente). Ao observar a ocorrência ao longo de todas as restingas do estado, notou-se uma grande variedade de tamanhos. Muitos indivíduos apresentaram somente parte das características da variedade nana, por isso optouse em não adotar essa delimitação. Cecropia lyratiloba se distingue de $C$. pachystachya Trécul pelas lenticelas esparsas ou raras, geralmente distantes mais de $5 \mathrm{~cm}$ (Carauta 1996).

6. Coussapoa Aubl., Hist. Pl. Guiane 2: 955, t. 362, 363. 1775.

Árvores, arbustos ou hemi-epífitas, ramos medulosos, dióicas, sem acúleos e tricomas urticantes, látex branco ou hialino. Folha inteira, peninérvea, bordo liso. Estípula conada e caduca deixando cicatriz amplexicaule. Inflorescência em capítulos globosos, pareados ou ramificados. Flor actinomorfa, perigônio tubuloso; estaminada 2lobada, 2 estames, filetes retos no botão, ausência de pistilódio; pistiladas com perigônio único, estigma penicilado-capitado. Fruto glabro, mergulhado no perianto alargado e carnoso. 
Gênero com 46 espécies distribuídas do sul do México ao sudeste do Brasil, ausente nas Antilhas (Berg et al. 1990). Nas restingas fluminenses está representado por apenas uma espécie.

\subsection{Coussapoa microcarpa (Schott) Rizzini,} Dusenia 1(5): 295. 1950.

Árvores 3-15 m de alt., látex branco ou hialino. Caule frequentemente bastante ramificado desde a base; ramos hirsutos. Estípula terminal 1,5$3,5 \mathrm{~cm}$, verde ou brúnea, glabra a tomentosa, prateada. Folha com pecíolo $1,1-3,7 \mathrm{~cm}$, glabro a puberulento; lâmina elíptico-ovada, 5,2-16 × 1,9$7,2 \mathrm{~cm}$, coriácea, base cuneada, ápice agudo, cuspidado, bordo inteiro, glabra em ambas as faces; nervuras secundárias 6-7 pares. Inflorescência alva, verde-amarelado a avermelhada; estaminada com ramificações de 3 ou mais capítulos globosos, pedúnculo comum 1-2 cm; pistilada solitária ou aos pares, pedúnculo comum 0,7-2,9 cm. Flores estaminadas 2 segmentos no perigônio; 2 estames alvos, filetes unidos, extrorsos quando maduros; flores pistiladas 1-2 mm. Fruto $1 \mathrm{~cm}$ de diâm., alaranjado.

Material selecionado: RIO DE JANEIRO: Angra dos Reis, Praia do Sul, IV.1996, L.E.Mello-Filho 5835 et al. (R). Araruama, 29.VIII.1983, D.Araujo 5656 et al. (GUA). Cabo Frio, Condomínio Florestinha, 2.IV.2008, L.C.Pederneiras 401 et M.S.Faria (R). Parati, Trindade, 22.VIII.1991, R.Marquete 332 et al. (RB). Rio de Janeiro: Barra da Tijuca, 17.VIII.1965, W.Hoehne 6055 (RB); Grumari, 12.III.1983, D. Araujo 5667 et N.C.Maciel (GUA). São João da Barra, Grussaí, 16.V.1989, D.Araujo 8841 (GUA). Saquarema, Jacarepiá, 17.I.2008, L.C.Pederneiras 357 et A.F.P.Machado (R).

Coussapoa microcarpa é endêmica do Brasil, encontrada na floresta ombrófila densa atlântica e estacional semidecidual, de Pernambuco ao Rio Grande do Sul. Nas restingas fluminenses ocorre sete localidades (São João da Barra, Barra de São João, Cabo Frio, Rio de Janeiro, Grumari, Praia do Sul e Parati), com extensão de ocorrência ca. $14100 \mathrm{~km}^{2}$, na formação arbustiva fechada e mata seca. Na Restinga de Jacarepiá, em Saquarema, foram observados pequena população de 2 a 3 indivíduos. Ocorre em São João da Barra, grande faixa arenosa deteriorada do nordeste do estado, mas na restinga preservada de Jurubatiba, logo abaixo, nunca houve registro. A proporção da população global presente nas restingas é de $13 \%$. Cumpre com os critérios de VU B1, mas a espécie ocorre nas vizinhanças das restingas, ou seja, uma fonte de imigração de propágulos que diminui uma categoria. Próximo a ameaçado, NT.
7. Laportea Gaudich., Voy. Uranie, Bot. 498. 1830.

Ervas monóicas, ramos medulosos, tricomas urticantes presentes em seus ramos e folhas, acúleos ausentes, látex hialino. Estípulas intrapeciolares, inteiras ou partidas no ápice. Folhas inteiras, peninérveas, bordo dentado. Inflorescências em panículas, bissexuais, flores estaminadas no ápice do ráque. Flores com tépalas livres providas de tricomas translúcidos; estaminadas actinomorfas, 4 5 tépalas iguais, 4-5 estames, filetes curvos no botão, presença de pistilódio; pistiladas zigomorfas, 4 tépalas desiguais, estigmas filiformes. Aquênios perpendiculares ao eixo e perianto persistente.

Gênero pantropical, com 22 espécies no total. Na América do Sul duas espécies são encontradas, Laportea aestuans (L.) Chew e L. interrupta (L.) Chew. No Brasil somente ocorre Laportea aestuans (Chew 1969).

7.1 Laportea aestuans (L.) Chew, Gard. Bull. Singapore 21 (2): 200. 1965.

Ervas até 1,5 $\mathrm{m}$ de alt., monóicas. Estípulas 5$7 \mathrm{~mm}$, terço inferior conato. Folhas com pecíolo 5$7,5 \mathrm{~cm}$, hirsuto; lâminas ovadas, $12-14 \times 8-11 \mathrm{~cm}$, membranáceas, base truncado-arredondada, ápice acuminado, bordo continuamente dentado, face adaxial glabrescente, abaxial glabra; nervuras secundárias 5-6 pares. Inflorescências hirsutas, 6$14 \mathrm{~cm}$ de compr. Flores estaminadas com bráctea basal, $1 \mathrm{~mm}$ de compr., tépalas alvas com 4-6 tricomas translúcidos no ápice, pistilódios claviformes, anteras alva; flores pistiladas com tépalas alvas, tépalas basais providas de 3-6 tricomas translúcidos. Aquênios 1-1,5 mm.

Material examinado: RIO DE JANEIRO: Cabo Frio, Condomínio Florestinha, 9.VI.2008, L.C.Pederneiras 464 et al. (R); 15.III.1996, L.E.Mello-Filho 5898 et al. (R). Rio de Janeiro, Jacarepaguá, IX.1916, F.C.Hoehne (SP 24900); Prainha, 28.X.1971, D.Sucre 7844 (RB); Restinga da Tijuca, 16.VI.1946, O.X.B.Machado (RB 75581).

Laportea aestuans é uma espécie pantropical. No Brasil ocorre na floresta ombrófila densa atlântica e amazônica, ombrófila aberta, estacional semidecidual e decidual e caatinga. Nas restingas fluminenses ocorre em três localidades (Barra de São João, Rio de Janeiro e Grumari), com extensão de ocorrência ca. $90 \mathrm{~km}^{2}$, na Formação de Mata Seca degradada, em terrenos em regeneração e próxima ao calçamento de condomínios. A proporção da população global da espécie presente nas restingas não foi estimada porque não foram visitados todos os herbários das regiões de sua distribuição 
geográfica. A espécie ocorre nas vizinhanças das restingas, sendo uma fonte de imigração de propágulos e, por isso, diminui-se uma categoria do passo dois. Em perigo, EN B1.

Frequentemente Laportea aestuans é confundida com espécies de Urera, em especial $U$. aurantiaca, devido ao hábito herbáceo, folhas ovadas e de bordo dentado. Porém Laportea aestuans diferencia-se de Urera por ser uma planta monóica ( $v s$. dióicas).

\section{Urera Gaudich. Voy. Uranie, Bot. 496. 1830.}

Ervas ou arbustos, dióicos, ramos medulosos, acúleos e tricomas urticantes presentes em seus ramos e folhas, látex branco ou hialino. Estípulas intrapeciolares, inteiras ou partidas no ápice. Folhas inteiras, peninérveas, bordo dentado a onduladodentado. Inflorescências em dicásios. Flores com tépalas livres, glabras; estaminadas actinomorfas, 4-5 tépalas iguais, 4-5 estames, filetes curvos no botão, presença de pistilódio; pistiladas zigomorfas, 4 tépalas desiguais, estigmas penicilado-capitado. Aquênios retos ao eixo e parcialmente fechados pelo perianto.

Gênero com ca. 50 espécies distribuídas pelas zonas tropicais do mundo (Steinmann 2005). No Brasil ocorrem oito espécies (Carauta 1967) e nas restingas fluminenses duas espécies.

8.1 Urera aurantiaca Wedd., Ann. Sci. Nat. Bot., sér. 3. 18: 201. 1852.

Fig. 2 a-d

Arbustos ca. 1,5 m. Estípulas 1-1,2 cm. Folhas com pecíolos 3-4 cm, glabros; lâminas ovadas, 8$15 \times 4,5-7,5 \mathrm{~cm}$, membranáceas, base cordada, ápice agudo, bordo regularmente dentado, ou crenado quando jovem, face adaxial glabra e abaxial pubescente; nervuras secundárias 6-8 pares. Inflorescências em dicásios perfeitos; estaminadas formando glomêrulos nos ápices, até $3 \mathrm{~cm}$ de compr.; pistiladas distribuidas uniformemente nos ramos, até $5 \mathrm{~cm}$ de compr. Flores pistiladas com tépalas com máculas arredondadas claras, estiletes curtos, retos.

Material examinado: RIO DE JANEIRO: Cabo Frio, Condomínio Florestinha, 15.III.1996, L.E.Mello-Filho 5898 et al (R); Estação de Rádio da Marinha, 15.V.1993, R.Mello-Silva 871 et Pirani (SP). Maricá, Ponta Negra, 25.IV.1943, J.Vidal (R 38969). Rio de Janeiro, Jacarepaguá, 15.III.1933, J.Vidal (R 58519).

Urera aurantiaca distribui-se da Colômbia a Argentina. No Brasil ocorre em floresta ombrófila densa atlântica e amazônica, estacional semidecidual e cerrado. Nas restingas fluminenses ocorre em três localidades (Barra de São João, Maricá e Rio de Janeiro), com extensão de ocorrência ca. 740 km², em Formação de Mata Seca degradada. A proporção da população global da espécie presente nas restingas não foi estimada porque não foram visitados todos os herbários das regiões de sua distribuição geográfica. A espécie ocorre nas vizinhanças das restingas, sendo uma fonte de imigração de propágulos e, por isso, diminui-se uma categoria do passo dois. Vulnerável, VU B1.

8.2 Urera nitida (Vell.) Brack, Napaea 1: 7. 1987.

Fig. 3 a-e

Arbustos 1-2 m de alt., látex branco. Caules e ramos verdes, aculeados. Estípulas 5-9 mm. Folhas com pecíolos 4-9 cm, glabros, espinhos urticantes esparsos, curtos, até ca. $2 \mathrm{~mm}$; lâminas elípticas, 18,5-24,5 × 7-12,5 cm, membranáceas, base arredondada a truncada, ápice cuspidado, bordo ondulado-dentado, ca. 1-2,5 cm entre-dente, face adaxial glabra com espinhos esparsos espalhados, $1-1,5 \mathrm{~mm}$ cada, face abaxial glabra com espinhos nas nervuras; nervuras secundárias 6-7 pares. Inflorescências em dicásios irregulares, raque vináceo, espinhos urticantes translúcidos a alvos; estaminadas escorpióides, 2-4 cm; pistiladas congestas ao redor do caule, geralmente se misturando com a inflorescência posterior, até 8 $\mathrm{cm}$. Flores estaminadas $2-3 \mathrm{~mm}$; flores pistiladas $0,5-1,5 \mathrm{~mm}$, tépalas alvas, estiletes até $1 \mathrm{~mm}$, curvos. Frutos 2-3 mm de compr.

Material examinado: RIO DE JANEIRO: Cabo Frio: APA do Pau Brasil, 9.VI.2008, L.C.Pederneiras 456 et al. (R); Estação de Rádio da Marinha, 29.X.2008, L.C.Pederneiras 490, 492, 493 et R.W.Lacerda (R); Condomínio Florestinha, 2.IV.2008, L.C.Pederneiras 399 et M.S.Faria (R). Mangaratiba, Restinga de Marambaia, ao lado do Posto de Saúde, 5.V.2008, L.C.Pederneiras 424 et al. (R). Parati, enseada de ParatiMirim, Praia das Almas, 13.VI.1994, T.Konno 410 et al. (RB). Rio de Janeiro, Ipanema, 1917, C.Diogo 807 (R). Rio das Ostras, Restinga do Balneário das Garças, 10.V.2000, H.N.Braga 1093 et Damasceno (RB).

Urera nitida distribui-se na América Tropical. No Brasil, ocorre na floresta ombrófila densa atlântica e amazônica, estacional semidecidual e decidual e caatinga. Nas restingas fluminenses ocorre em seis localidades (Barra de São João, Cabo Frio, Baia de Guanabara, Grumari, Marambaia e Parati), com extensão de ocorrência ca. 4000 km², na Formação de Mata Seca degradada em processo 


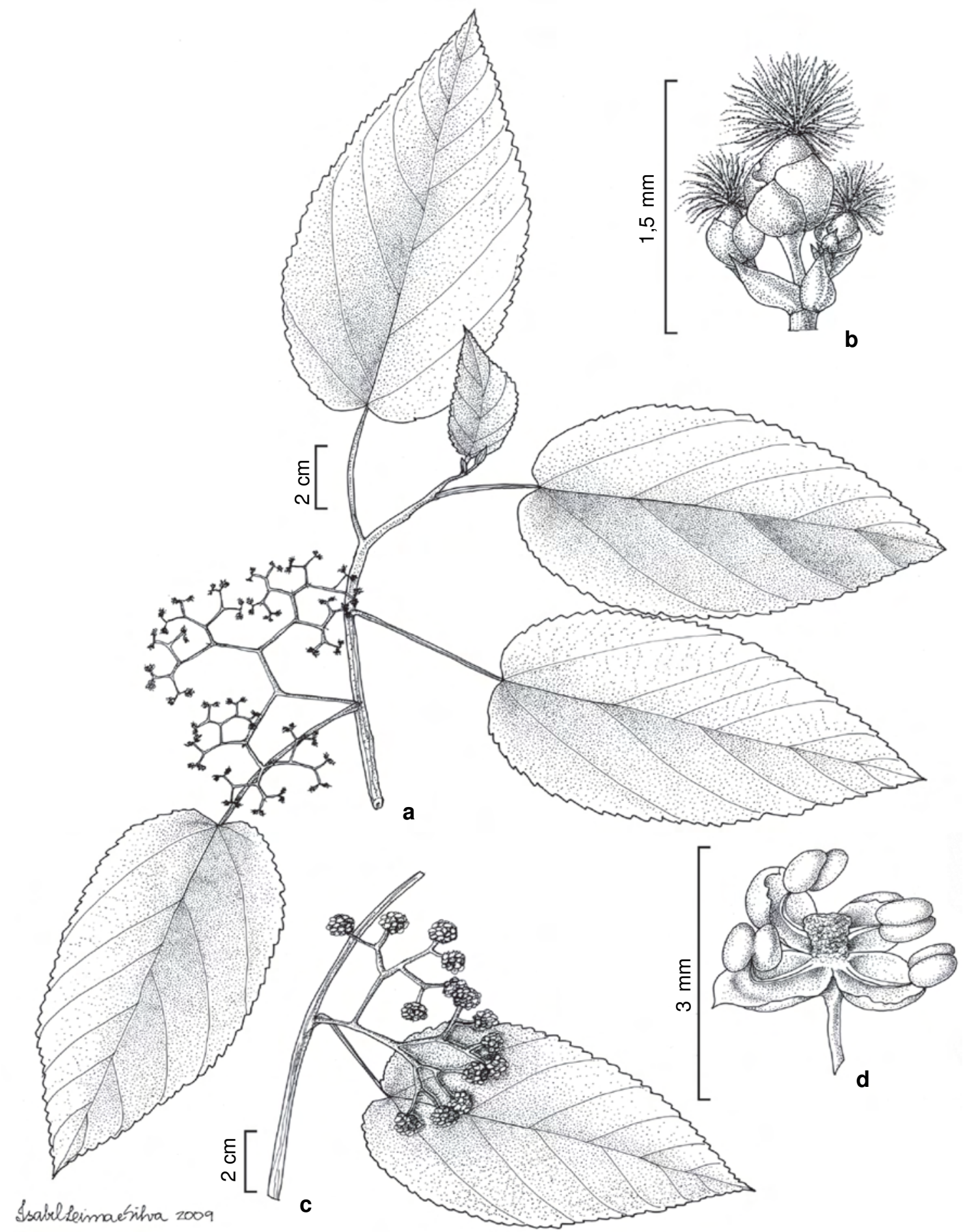

Figura 2 - Urera aurantiaca Wedd. - a. ramo pistilado; b. flores pistiladas; c. ramo estaminado; d. flor estaminada (a,b Rangel et Schwacke s/n (R 39396); c,d A.J.Sampaio 7248).

Figure 2 - Urera aurantiaca Wedd. - a. pistillate twig; b. pistillate flowers; c. staminate twig; d. staminate flower (a,b Rangel et Schwacke s/n (R 39396); c,d A.J.Sampaio 7248). 


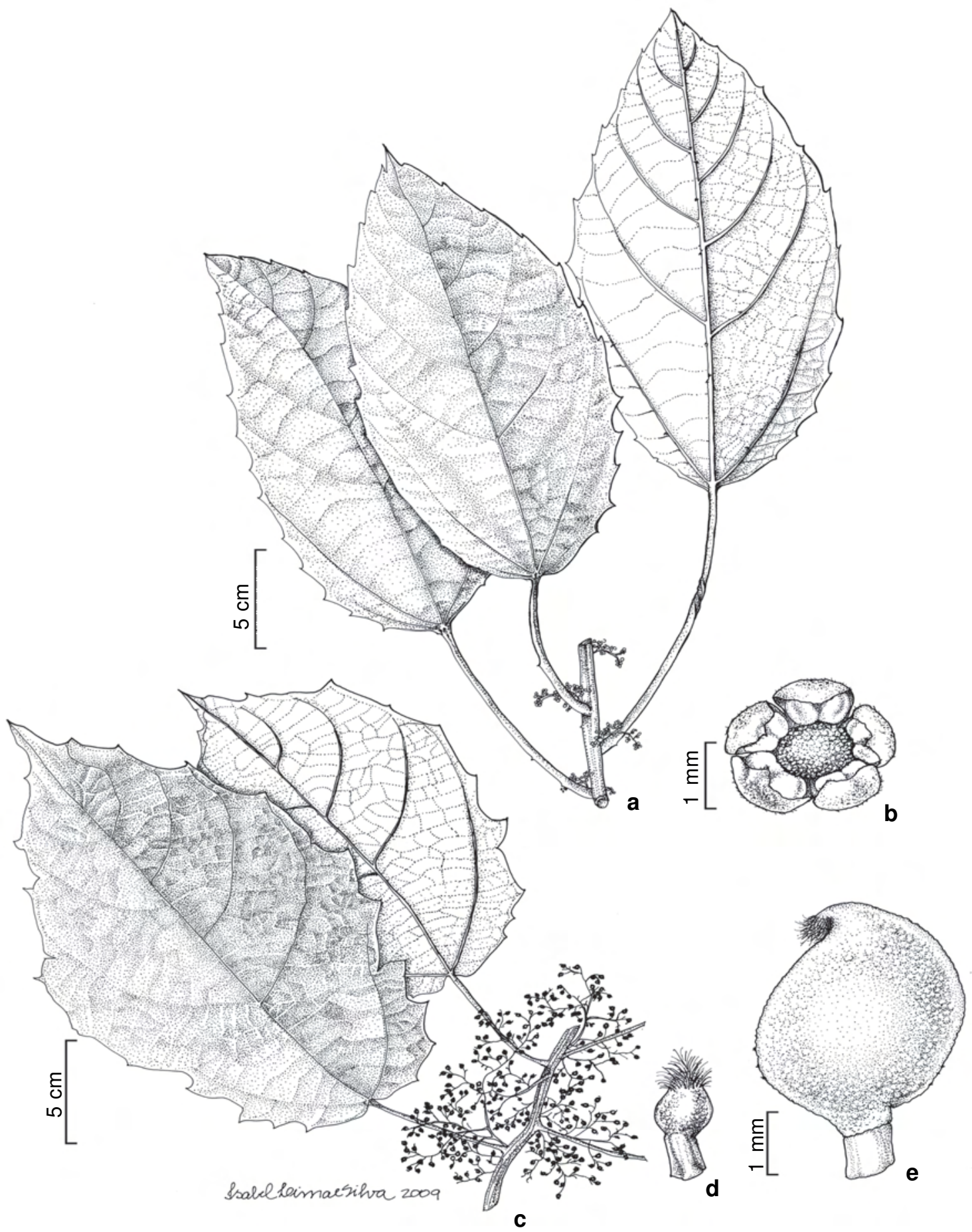

Figura 3 - Urera nitida (Vell.) Brack - a. ramo estaminado; b. flor estaminada; c. ramo pistilado; d. flor pistilada; e. fruto (a, b L.C.Pederneiras 559; c-e L.C.Pederneiras et al. 424).

Figure 3 - Urera nitida (Vell.) Brack - a. staminate twig; b. staminate flower; c. pistillate twig; d. pistillate flower; e. fruit (a,b L.C.Pederneiras 559; c-e L.C.Pederneiras et al. 424). 
de regeneração. A proporção da população global da espécie presente nas restingas não foi estimada porque não foram visitados todos os herbários das regiões de sua distribuição geográfica. A espécie ocorre nas vizinhanças das restingas, sendo uma fonte de imigração de propágulos e, por isso, diminui-se uma categoria do passo dois. Vulnerável, VUB1.

\section{Agradecimentos}

Ao CNPq a concessão de bolsa de Mestrado ao primeiro autor. A Marinha do Brasil e a empresa LLX a autorização de coleta em Campos Novos e Lagoa de Grussai, respectivamente. Aos curadores e demais funcionários dos herbários visitados a permissão do uso de suas coleções. Aos colegas de excursão de campo e motoristas do departamento de transporte da UFRJ pelas excursões e auxílio de campo. Aos Dr. Sérgio Romaniuc-Neto, Dra. Regina Helena Potsch Andreata, Dra. Genise Vieira Somner e Dra. Claudia Petean Bove as sugestões prestadas. A Isabel Lima e Silva pelo preparo das ilustrações.

\section{Bibliografia}

Andrade, J.C. \& Carauta, J.P.P. 1981. Cecropia lyratiloba Miq. var. nana, nova variedade para o BrasilSudeste. Bradea 3: 163-169.

APG. 2009. An update of the Angiosperm Phylogeny Group classification for the orders and families of flowering plants: APG III. Botanical Journal of the Linnean Society 161: 105-121.

Araujo, D.S.D. 2000. Análise florística e fitogeográfica das restingas do Estado do Rio de Janeiro. Tese de Doutorado. Universidade Federal do Rio de Janeiro, Rio de Janeiro. 176p.

Araujo, D.S.D. \& Maciel, N.C. 1998. Restingas fluminenses: biodiversidade e preservação. Boletim FBCN 25: 27-51.

Araujo, D.S.D.; Scarano, F.R.; Sá, C.F.C.; Kurtz, B.C.; Zaluar, H.L.T.; Montezuma, R.C.M. \& Oliveira, R.C. 1998. As comunidades vegetais do Parque Nacional da Restinga de Jurubatiba, Macaé, RJ. In: Esteves, F.A. (ed.). Ecologia das lagoas costeiras do Parque Nacional da Restinga de Jurubatiba e do Município de Macaé (RJ). NUPEM-UFRJ, Rio de Janeiro. Pp. 39-62.

Berg, C.C.; Akkermans, R.W.A.P. \& Heusden, E.C.H. van 1990. Cecropiaceae: Coussapoa and Pourouma, with an introduction to the family. Flora Neotropica 51: $1-208$.

Berg, C.C. \& Dahlberg, S.V. 2001. A revision os Celtis subg. Mertensia (Ulmaceae). Brittonia 53: 66-80.
Berg, C.C. \& Rosselli, F. 2005. Cecropia. Flora Neotropica 94:1-230.

Brack, P. 1987. O gênero Urera (Urticaceae) no Rio Grande do Sul, Brasil. Napaea 1:1-11.

Burger, W. 1977. Ulmaceae, Moraceae, Cannabaceae, Urticaceae. In: Burger, W.C. (ed.). Flora costaricensis. Fieldiana, Botany 40:83-291.

Carauta, J.P.P. 1967. Catálogo dos gêneros das Urticaceae do Brasil. Imprensa da Universidade Federal do Paraná, Curitiba. 11p.

Carauta, J.P.P. 1969. Ulmaceae da Flórula Carioca, lista das espécies. Atas da Sociedade de Biologia do Rio de Janeiro 12: 217-219.

Carauta, J.P.P. 1971. Notas sobre o gênero Phyllostylon Cap. (Ulmaceae). Revista Brasileira de Biologia 31: 513-518.

Carauta, J.P.P. 1996. Moraceae do estado do Rio de Janeiro. Albertoa 4: 145-194.

Chew, W.L. 1969. Monograph of Laportea. Gardens' Bulletin Singapore 25: 111-178.

Cronquist, A. 1988. The evolution and classification of flowering plants. 2nd ed. The New York Botanical Garden, New York. 555p.

Hadiah, J.T.; Conn, B.J. \& Quinn, C.J. 2008. Infra-familial phylogeny of Urticaceae, using chloroplast sequence data. Australian Systematic Botany 21: 375-385.

IUCN. 2001. IUCN Red List categories and criteria: Version 3.1. IUCN Species Survival Commission, Gland and Cambridge. 30p.

IUCN. 2003. Guidelines for application of IUCN red list criteria at regional levels. Version 3.0. IUCN Species Survival Comission, Gland and Cambridge. 26p.

Judd, W.S.; Campbell, C.S.; Kellogg, E.A.; Stevens, P.F. \& Donoghue, M.J. 2009. Sistemática vegetal, um enfoque filogenético. $3^{\mathrm{a}}$ ed. Artmed, Porto Alegre. 632p.

Lawrence, G.H.M. 1971. Taxonomy of vascular plants. Macmillan, New York. 823p.

Miller, R.M.; Rodríguez, J.P.; Aniskowicz-Fowler, T.; Bambaradeniya, C.; Boles, R.; Eaton, M.A.; Gärdenfors, U.; Keller, V.; Molur, S.; Walker, S. \& Pollock, C. 2007. National threatened species listing based on IUCN criteria and regional guidelines: current status and future perspectives. Conservation Biology 21: 684-696.

Miquel, F.A.G. 1853. Urticineae. In: Martius, C.F.P.von; Eichler, A.W. \& Urban, I. Flora brasiliensis. Munchen, Wien, Leipzig 4: 77-218. Tab. 25-70.

Mori, S. A.; Silva, L.A.M.; Lisboa, G. \& Coradin, L. 1989. Manual de manejo do herbário fanerogâmico. $2^{a}$ ed. Centro de Pesquisas do Cacau, Ilhéus. 104p.

Pederneiras, L.C. 2009. Urticales das restingas do estado do Rio de Janeiro: flora e padrões de distribuição geográfica. Dissertação de Mestrado. Universidade Federal do Rio de Janeiro, Rio de Janeiro. 166p. 
Planchon, J.E. 1873. Ulmaceae. Prodromus Systematis Naturalis Regni Vegetabilis 17: 151-210.

Radford, A.E.; Dickinson, W.C.; Massey, J.R. \& Bell C.R. 1974. Vascular plant systematics. Harper et Row, Nova York. 891p.

Rocha, E.S.F.; Carauta, J.P.P. \& Lima, D.F. 2000. Ulmáceas do estado do Rio de Janeiro, nota preliminar. Albertoa Serie Urticiniae, Urticales 2: 9-15.

Romanczuk, M.C. \& Martínez, M.A.P. 1978. Las especies del género Celtis (Ulmaceae) en la flora Argentina. Darwiniana 21: 541-577.

Romaniuc-Neto, S. 1992. Urticaceae. In: Melo, M.M.R.F.; Barros, F.; Chiea, S.A.C.; Kirizawa, M.; Jung-Mendaolli, S.L. \& Wanderley, M.G.L. (eds.). Flora fanerogâmica da Ilha do Cardoso. Vol. 3. SEMA, São Paulo. Pp. 161-165.

Romaniuc-Neto, S.; Gaglioti, A.L. \& Guido, B.M.O. 2009. Urticaceae Juss. do Parque Estadual das Fontes do Ipiranga, São Paulo, SP, Brasil. Hoehnea 36: 193-205.

Segadas-Vianna, F., Ormond, W.T. \& Dau, L. 1965/78. Flora ecologica das restingas do sudeste brasileiro. Universidade Federal do Rio de Janeiro, Rio de Janeiro. $22 \mathrm{v}$.

Souza, V.C. \& Lorenzi, H. 2005. Botânica Sistemática: Guia ilustrado para identificação das famílias de angiospermas da flora brasileira, baseado em APGII. Instituto Plantarum, Nova Odessa. 640p.

Steinmann, V.W. 2005. Urticaceae. Flora del Bajío y de regiones adjacentes. 134: 1-74.

Sytsma, K.J.; Morawetz, J.; Pires, J.C.; Nepokroeff, M.; Conti, E.; Zjhra, M.; Hall, J.C. \& Chase, M.W. 2002. Urticalean rosids: circumscription, rosid ancestry, and phylogenetics based on rbcL, trnL-F, and ndhF sequences. American Journal of Botany 89: 1531-1546.

Thiers, B. 2010 [continuously updated]. Index Herbariorum: a global directory of public herbaria and associated staff. New York Botanical Garden's Virtual Herbarium. Disponível em: <http:// sweetgum.nybg.org/ih>. Acesso em jun 2010.

Todzia, C.A. 1989. A revision of Ampelocera (Ulmaceae). Annals of the Missouri Botanical Garden 76: 1087-1102.

Todzia, C.A. 1992. A reevaluation of the genus Phyllostylon (Ulmaceae). Sida 15: 263-270.

Torres, R.B. \& Luca, A.Q. 2006. Ulmaceae. In: Wanderley, M.G.L. Shepherd, G.J.; Melhem, T.S. \& Giulietti, A.M. (eds.). Flora fanerogmica do estado de São Paulo. Vol. 4. FAPESP, São Paulo. Pp. 361-369.

Ule, E. 1967. A vegetação de Cabo Frio. Boletim Geográfico do Rio de Janeiro 26: 21-32.

Vasconcellos, J.C. 1969 Noções sobre a morfologia externa das plantas superiores. $3^{\mathrm{a}}$ ed. Série Estudos e Informação Técnica. Serviço Editorial da Repartição de Estudos, Informação e Propaganda, Lisboa. 227p.

Vellozo, J.M.C. 1881. Flora Fluminensis. Vol. 5. Archivos do Museu Nacional do Rio de Janeiro.

Veloso, H.P.; Rangel-Filho, A.L.R. \& Lima, J.C.A. 1991. Classificação da vegetação brasileira, adaptada a um sistema universal. Instituto Brasileiro de Geografia e Estatística, Rio de Janeiro. 123p.

Wiegrefe, S.J., Sytsma, K.J. \& Guries, R.P. 1998. The Ulmaceae, one family or two? Evidence from chloroplast DNA restriction site mapping. Plant Systematics and Evolution 210: 249-270. 